\title{
ITRU UAK-1 +1 Fiber Length and Neps Size Distribution Measurement from Fiber Beard
}

\author{
Fatih KALLi \\ Itru Group Ltd, Istanbul, Topkapı Center No: 207, 34020, İstanbul, Turkey
}

\begin{abstract}
Itru Group has developed the "Itru UAK-1+ Cotton Fiber/Fabric Information System" to measure Length and Neps Size distribution from fiber beard. The importance of this system Length and Neps Size distribution takes at the same time along with the Length and Neps Size Distribution . Coefficient of Fiber Straightness Variation, Surface Damaged Fibers Percentage also measured. These new parameters could be used to check the hooked fibers in processing stages in ginning, spinning and genetics research on cotton fibers. The field of application of this system also include card flat waste, comber noil and blow room waste and all processing stages from bale to ring frame delivery. Cotton Fiber Neps size distribution in relation to Dyed Fabric appearance has been analyzed. It has been found that 5\% Neps Size Distribution is closely related to Dyed Fabric Neps appearance. Neps Index measured at the comber deliverywhich is related to deviation from Fiber Surface structure is closely correlated with the yarn neps per $1 \mathrm{~km}$.
\end{abstract}

Keywords: Fiber length distribution, fiber beard, neps index, \% surface damaged fiber, short fiber content \%, card flat waste, comber noil.

\section{INTRODUCTION}

\subsection{Testing Machine}

Itru Fiber/Fabric Tester UAK-1+developed by Turk engineers is an innovative state of an art technology fibre/sliver/spinning technology Information system : that measures the important parameters of all types of fibers, waste, slivers and fabrics, reporting comprehensive and detailed analyses, bringing new conception to textile technology with new terms and definitions .

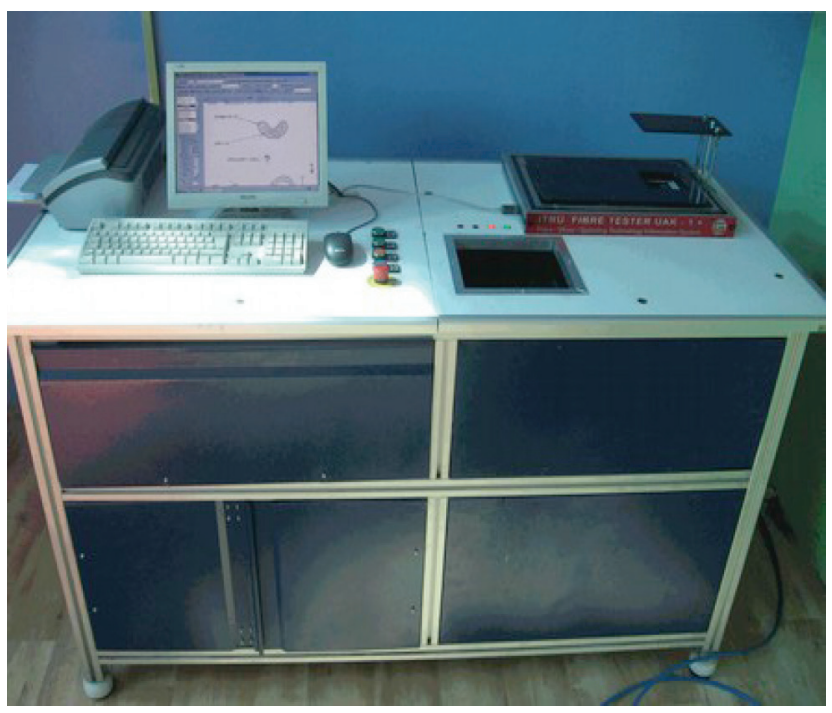

Figure 1. Fiber/Fabric Tester UAK-1
The system consists of following main sections:

- Fiber Tester UAK-1+ ver 1.1 software

- Completely automatic measurement systems (mechanic, electronic, pneumatic) and image analyzers

- Computer with Ms-Windows operating system, mouse and keyboard

- TFT slight monitor screen and a printer and fully automated fibre/sliver feeding and cleaning system.

UAK-1 + measurements are based upon the direct measurement of scanned samples images therefore no calibration is required. The machine is delivered as ready to be run. Therefore, no installation costs. All the spare parts could be find in local market and can be replaced with your technical personnel i.e. low cost maintenance and easy maintenance and easy to run

\subsection{Operation Principle}

Fiber Beard is formed on Fiber Clamp Unit from Fiber/ Sliver by specially designed air flow systems, brush rollers and brushes. Fiber Feeding and cleaning of all system are carried out automatically by air flow systems and brush rollers. Machine Running Video (http://itru.net/uaktech/ uak-1+.wmv)(Windows Media Player File)

Time taken for each cycle can be varied from 20 to $40 \mathrm{sec}$

Corresponding Author: Fatih Kalli, Tel: +90 (212) 285 61 83, E-mail: itrultd@gmail.com

Submitted: 15 October 2014, Revised: 04 March 2015, Accepted: 01 July 2015 
depending upon the type of material used. Dimensions: Length $=1595 \mathrm{~mm}$, Width $=600 \mathrm{~mm}$, Height $=895 \mathrm{~mm}$, Weight $=250 \mathrm{~kg}$, Requirements: Compressed air inlet for 6-8 bar pressure 220 volt power supply

\subsection{Testing Methods, Test Reports Results and Test Parameters}

All UAK tests methods base upon image processing techniques and Alherizmi Path (Algorithms) .UAK-1 + provides following test reports, charts and images

Reports:

A comprehensive detailed single test results reports for 101 parameters

User defined test parameters of 2 summary test reports

User interactive and selective Fiber Data Base Test Reports for 50 parameters

\subsubsection{Length and Neps Distribution Test Results of Comber Sliver Front}

Table 1. Length and Neps Distribution Test Results

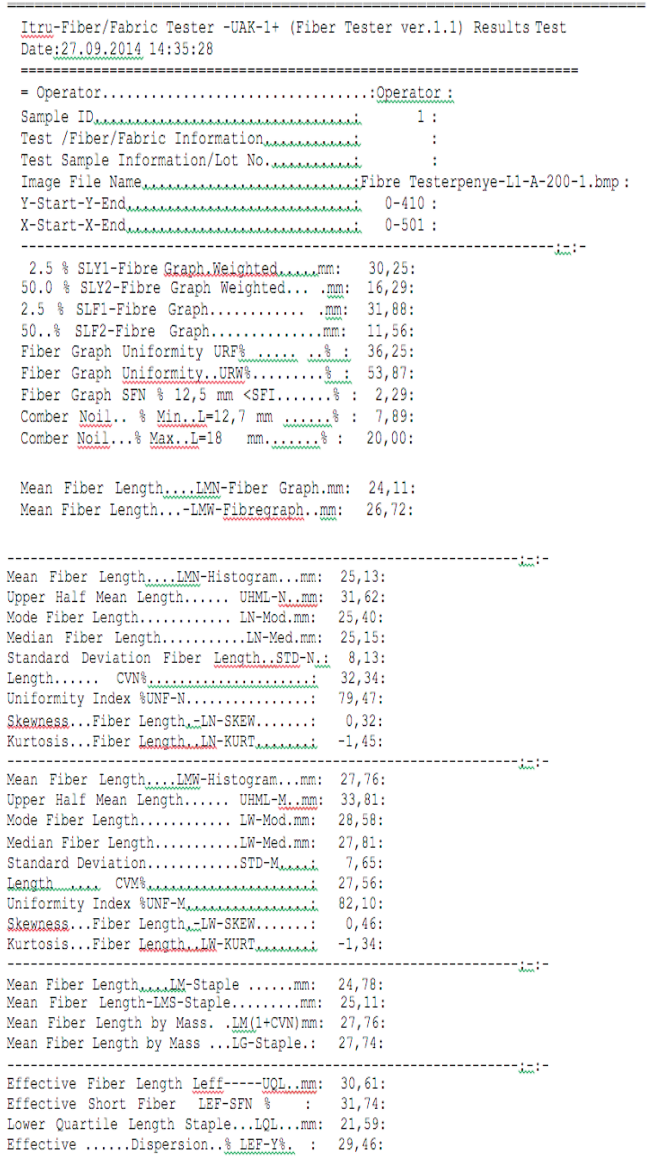

\begin{tabular}{|c|c|}
\hline Effective Fiber Length Leff- -UQLW.mm: & $32,39:$ \\
\hline Effective Short Fiber LEF-SFNw: : & 18, 38: \\
\hline Lower Quartile Length...Staple-IoLW..mm: & 22,99: \\
\hline Effective ......Dispersion) \& LEFWY : : & $29,02:$ \\
\hline 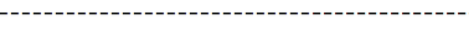 & --- \\
\hline 12.5m <Short Fiber Content SFNô, & 15,89: \\
\hline $6 \mathrm{~mm}<$ Very Short Fibres SFNK & 2,89: \\
\hline 18 mm<Short Fibres SFNCW Mass...: & $21,28:$ \\
\hline 12.5mm<Short Fibres SFNW:Mass ....... & $6,32:$ \\
\hline 1\% SL-Ratch Setting Distance.........mm: & 41,02: \\
\hline Absorption, & 6,98 \\
\hline 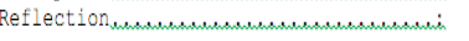 & 7,17 \\
\hline Cotton Classification-Process............. IO & NG STAPLE-IONG-CARDED/COMBED: \\
\hline Cotton Category...........A-B-C-D-E: & B: \\
\hline
\end{tabular}

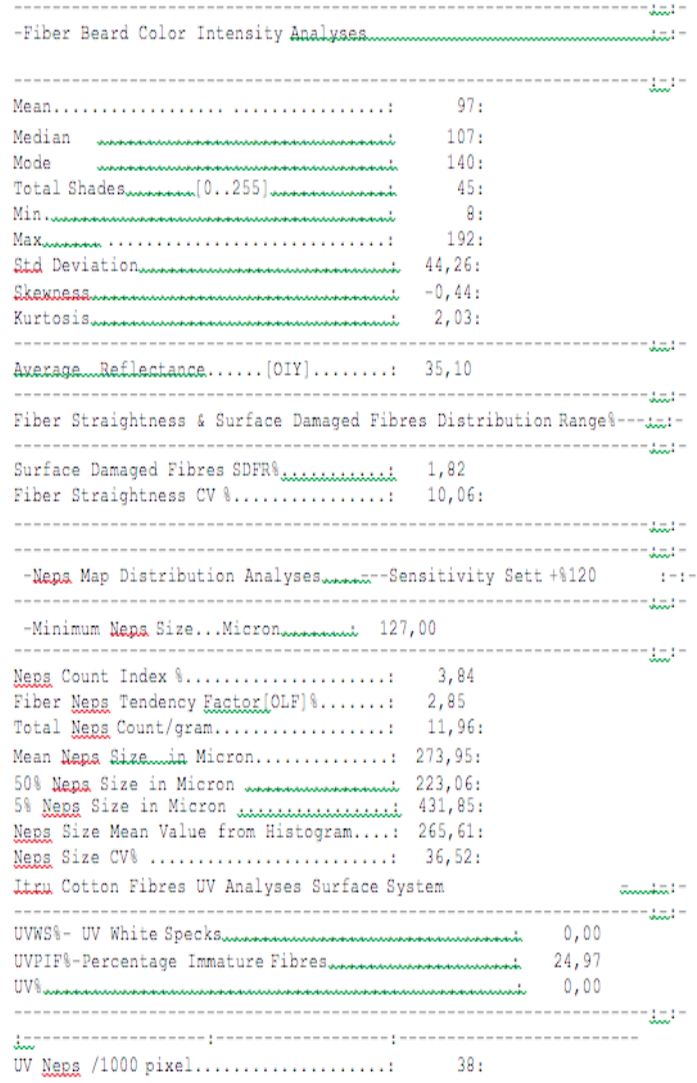

\subsection{Test Results from Fiber Beard}

Following test results are achieved from fibre beard image processing.

- $\quad$ Fibre Length and its distribution

- $\quad$ Short fibre content $\%$

- Neps Size Distribution

- Neps Web and Neps/Gram

- $\quad$ UV Neps \%

- $\quad$ CV\% fibre parallelism 
- $\quad$ Fiber surface damage

- Color of fibre beard and distribution

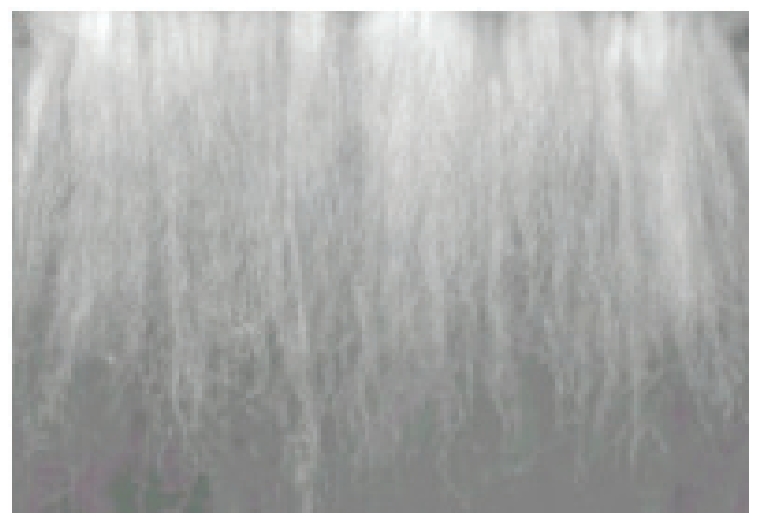

Figure 2. Fiber Beard

Average values of Fiber Fineness( mtex) Fiber Maturity(Theata) and Fiber Strength Presley (1/8 inch g/ tex ) have also been estimated from Fiber Beard but not yet implemented to the system The system could also be developed further to include measurement of percentages of seed coat fragments, trash and dust particulars. Therefore, image processing of fibre beard has much potential for the fibre and textile industry.

\begin{tabular}{lllll} 
& N & CV $\%$ & E\% & \multicolumn{2}{c}{ Q } \\
Sample Size & 40000 & 30 & 0,29 & 95 \\
Sample Size & 40000 & 30 & 0,45 & 99
\end{tabular}

\subsubsection{Fiber Length Distribution Measurement from Fiber Beard}

Fiber Length measurement starts from $0 \mathrm{~mm}$ to maximum fibre length. Fiber Clamp has been specially designed to minimize non measurable fibers held in the clamp. The sample image has a minimum multiplication of 8 times of the actual sample size. Total numbers of fibers are measured can vary from 30,000 to 45,000 User can also actually see the sample tested and also actually see the maximum fibre length value from the Sample Image of Fiber Beard. The accuracy of the system and standard error $(\mathrm{E} \%)$ of the Fibre Beard Image processing can be calculated as at 95 $\%$ and $99 \%$ confidence limits as The system 1st plots the Histogram of Optic Fiber Density(Number of Fibers) Histogram and Optic Mass Histogram (Fiber Weight) and from these two charts Staple Diagrams and Fiber Graph which is the 2nd Integral of the Histogram are plotted. Optic fibre density histogram resembles the Histogram of Fibre Length by number as normalized distribution [1] .

UAK-1 +1 length measurements especially as in the case of very fine fibers less than 150 mtex sample length measurements are not compatible with AFIS .
This could be related to many factors as explained by Chris Alan Braden [2] "There are a number of error sources in AFIS measurements". Fiber damage may occur during the separation of fibers by the individualizer on the AFIS prior to actual measurement. Bragg and Shofner (1993) indicated that the length distribution of fibers passing through the fiber individualizer is much the same as the length distribution of cotton passing through the cotton card. Cui et al. (2004) stated that there are fiber breakages in the opening unit between 1 to 4\%. Bragg and Shofner (1993) concluded that the UHM is reduced by $1-2 \mathrm{~mm}$ and that the SFC readings increase approximately $7 \%$ in comparison with slower, hand-sorting methods. Furthermore, only a portion of the fibers may be counted since both entangled and hooked fibers are excluded."

However, UAK-1 + Length measurements comparison with known samples are shown below with Sample Images.

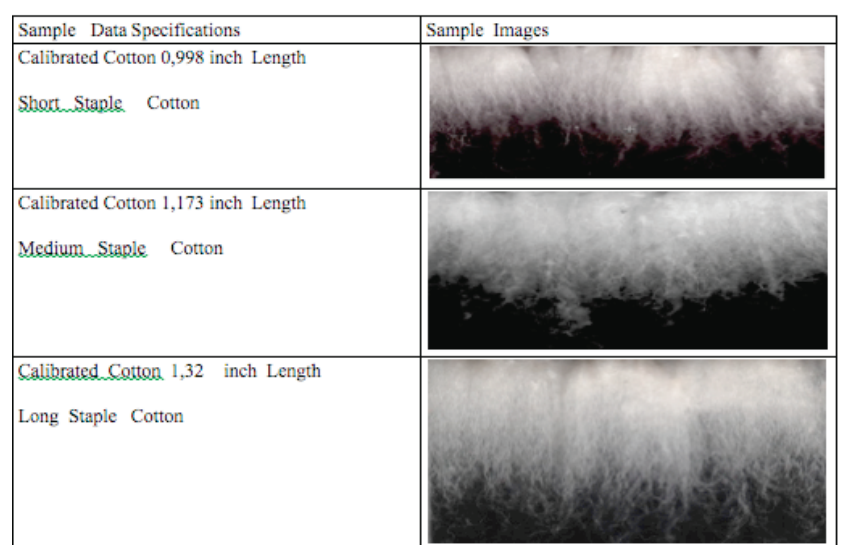

Figure 3. Fiber Length Measurement by Fiber Number of Calibrated Samples

We have no information about the how the calibrated cotton samples were calibrated. Itru UAK-1 + plots the absolute values that are measured from the fibre clamp. It is also possible to calibrate the samples from this Fiber Beard Image manually. At very high resolution such as 9600 pixel per inch and selecting 30 fibers randomly for five groups one can actually measure the real values of the calibrated cotton sample to check the calibrated values and compare these results with UAK-1 + measurements..

Fiber Clamp of UAK-1 + has been specially designed for image analysis and differs from other type of fibre clamps. Amount of non-measurable fibers were minimized and measurement as stated before starts from $0 \mathrm{~mm}$ of the fibre clamp to maximum fibre length. 
Table 2. Fiber Clamp of UAK-1 calibrated results
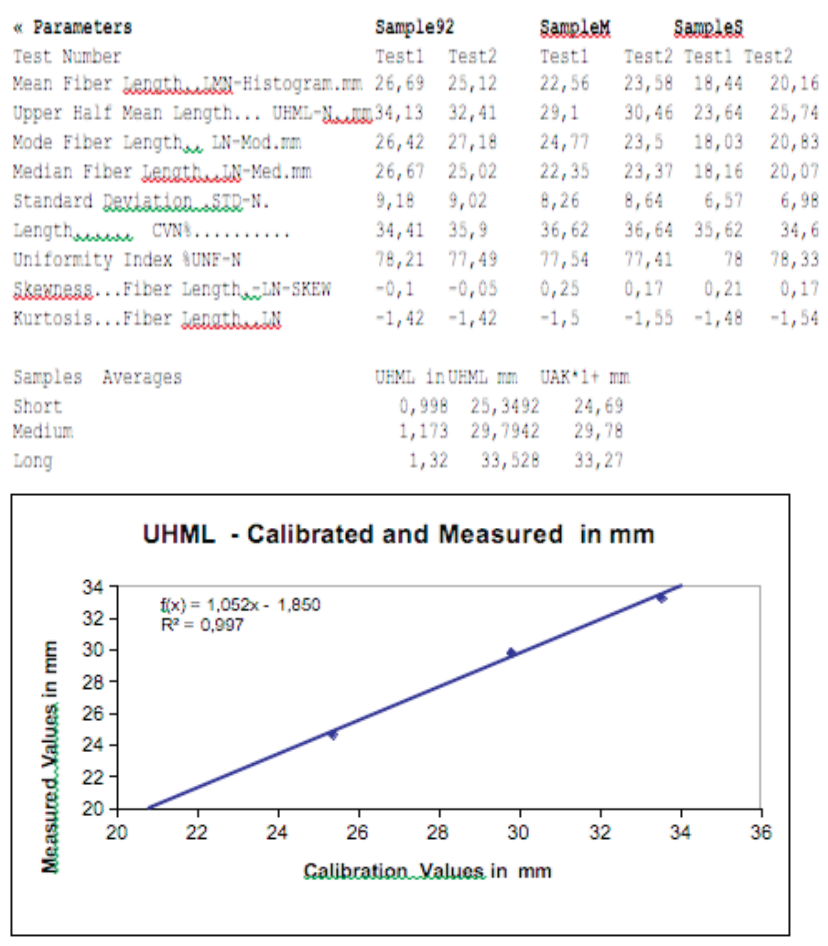

Figure 4. Calibrated and Measured (mm)

Uniformity Index = Mean Fiber Length by Number/ Upper Half Mean Length *100. These are uniformity index values by Fiber Number. Uniformity Index by fibre weight are higher since $\mathrm{CV} \%$ by fibre mass is much lower than $\mathrm{CV}$ $\%$ by fibre number.

Comber Noil Fiber Length Distribution could be checked by UAK- $1+1$ so that the spin able fibre $\%$ could be fined to minimize comber noil percentage in spinning process. A comparison table has given for 2 spinning mills.

Table 3. UAK-1 +Comber Noil Fiber Length by weight Comparison between 2 spinning Mills Mill A and Mill B

\begin{tabular}{|c|c|c|c|c|}
\hline Comber Noil Measurement Mill A & Test1 & & \multicolumn{2}{|c|}{ Average } \\
\hline Mean Fiber Length_oulmwl-Histogram....mm & & 20,2 & 22,42 & 21,31 \\
\hline Upper Half Mean Length & & 25,25 & 27,77 & 26,51 \\
\hline Mode Fiber Length.............. LW-Mod.mm & & 20,57 & 24,13 & 22,35 \\
\hline Median Fiber Length.............LW-Med.mm & & 20,07 & 22,48 & 21,275 \\
\hline Standard Deviation.............STD-M.... & & 6,32 & 6,63 & 6,475 \\
\hline Leagth & & 31,26 & 29,59 & 30,425 \\
\hline Uniformity Index \%UNF-M.................. & & 80,03 & 80,75 & 80,39 \\
\hline Skewaess...Fiber Length .LW-SKEW........ & & 0,24 & 0,01 & 0,125 \\
\hline Kurtosis...Fiber LeagtbulbQ-KURT omm & & $-1,46$ & $-1,5$ & $-1,48$ \\
\hline comber Noil Measurement Mill B & Test1 & & \multicolumn{2}{|c|}{ Average } \\
\hline Mean Fiber Length_mblMWL-Histogram....mm & & 15,87 & 16,54 & 16,205 \\
\hline Upper Half Mean Length & & 19,58 & 20,46 & 20,02 \\
\hline Mode Fiber Length.............. LW-Mod.mm & & 18,03 & 16 & 17,015 \\
\hline Median Fiber Length.............LW-Med.mm & & 15,88 & 16,38 & 16,13 \\
\hline Standard Deviation.............STD-M.... & & 4,72 & 4,98 & 4,85 \\
\hline Length & & 29,75 & 30,1 & 29,925 \\
\hline Uniformity Index \%UNF-M.................. & & 81,09 & 80,85 & 80,97 \\
\hline Skewaess...Fiber Length. - LW-SKEW........ & & 0,31 & 0,23 & 0,27 \\
\hline Kurtosis...Fiber LeagthualWW-KURT & & $-1,4$ & $-1,51$ & $-1,455$ \\
\hline
\end{tabular}

\begin{tabular}{|l|l|}
\hline Histogram Comber Sliver & Staple. Diagram Comber Sliver \\
\hline & \\
\hline & \\
\hline
\end{tabular}

Figure 5. Sliver diagrams

By testing the Mass Staple Diagram and Neps Distribution of comber lap one can select the optimum comber noil percentage. Comber Noil \% depends upon mainly following factors

- Short fibre content by weight of comber lap (less than half an inch)

- Short fibre content by weight of comber lap (less than $1 / 4$ inch)

- Neps size of Comber Lap at $5 \%$

Bashir Aziz, [2] has developed equations in relation to UHML (Upper Half Mean Length), Mean Length and Length CV \%

$U H M L N=M L *(1+k I * C V * 0,01)(1.3) U H M L W=M L *(1+k 1 * C V 0.01)(1.4)$

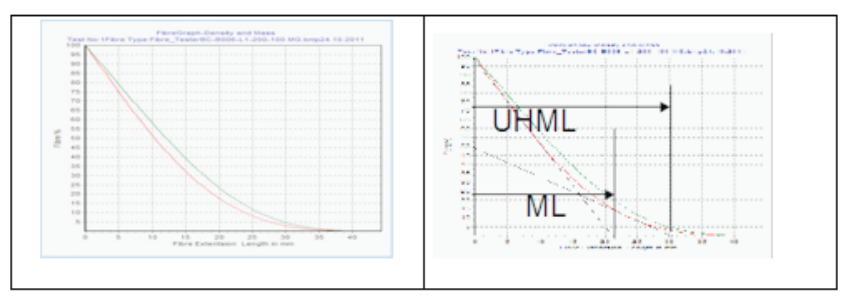

Figure 6. Itru Fiber Fabric Tester UAK-1 + Fiber Graph

Table 4. UAK-1 + UHML Calculated and Measured Correlation Table

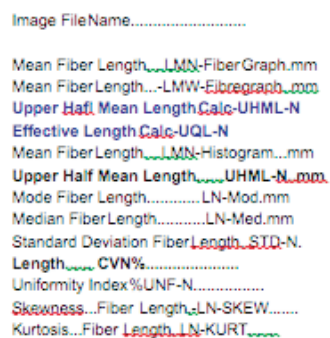

\begin{tabular}{rrrrr}
$-B 006-$ & $-B 007--$ & $B C-17$ & $B C-20$ & \multicolumn{1}{l}{$B C-19$} \\
$-\cdot-$ & - & & & \\
22,41 & 22,76 & 21,61 & 19,69 & 20,8 \\
25,42 & 25,98 & 24,42 & 22,21 & 23,65 \\
30,25 & 30,87 & 29,07 & 26,25 & 28,14 \\
29,16 & 29,75 & 28,02 & 25,33 & 27,12 \\
23,55 & 23,95 & 22,61 & 20,59 & 21,86 \\
30,33 & 30,95 & 29,15 & 26,31 & 28,25 \\
23,88 & 22,48 & 24,13 & 22,1 & 20,7 \\
23,5 & 23,75 & 22,61 & 20,7 & 21,84 \\
8,37 & 8,65 & 8,07 & 7,08 & 7,85 \\
35,54 & 36,12 & 35,7 & 34,39 & 35,89 \\
77,65 & 77,4 & 77,58 & 78,27 & 77,39 \\
$-0,02$ & $-0,11$ & $-0,02$ & 0 & $-0,09$ \\
$-1,49$ & $-1,4$ & $-1,4$ & $-1,52$ & $-1,49$
\end{tabular}




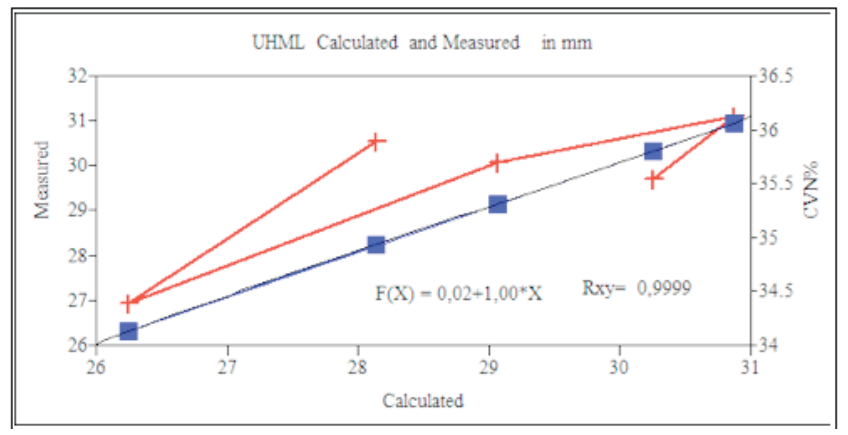

Figure 7. Itru RXY Scatter ver 1.1 Chart of Calculated and Measured UHML with CVN \% Values for 5 samples

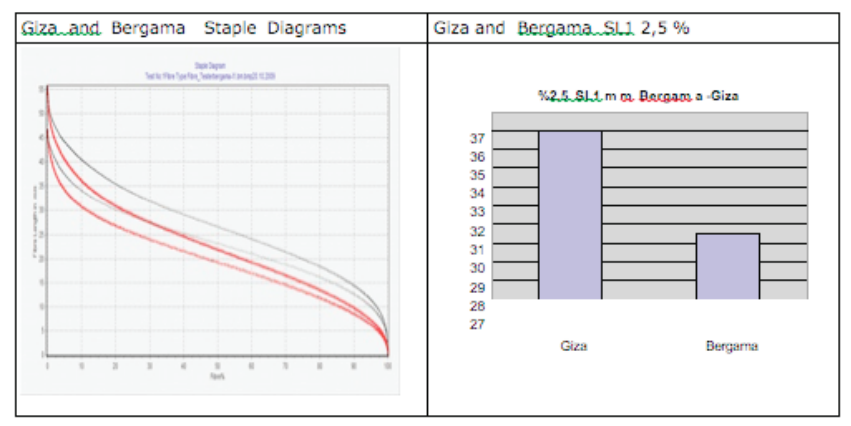

Figure 8. Comparison of Long Staple and Medium to Long Staple Cotton Origins

\subsubsection{Short Fiber Content \% Measurements:}

From Fiber Beard short fibers content percentage could be measured as by number and weight as absolute values less than $12 \mathrm{~mm}, 18 \mathrm{~mm}$ and $6 \mathrm{~mm}$. Short Fiber Content $\%$ also measured as relative to effective fibre length. This is useful to compare fibers which are in the same fibre class Itru Fiber Beard Neps Parameters Itru Fiber Neps measurement takes place directly from the fibre beard. The system plots Neps size distribution of Relative Frequency $\%$ Histogram and Integrated Cumulative Frequency \% Diagram (Fiber Graph) in relation to Neps Size in Microns from minimum 127 micron upwards.

From these two charts

a) CV \% Neps Size and Mean Neps Size in micron

b) Neps Size in micron $>50 \%$ of the sample

c) Neps Size in micron $>5 \%$ of the sample

d) Neps per gram of the sample

e) Neps Index \% (Deviation \% from Fiber Surface Structure) are measured.
In order to test the algorithms for the neps size measurement distribution, neps size are measured in microns manually for some samples. The chart gives the comparison of average neps size values and Neps Index (Deviation \% From Fiber Surface Structure ) measured on Combed Sliver with Neps Count Per km of yarn with same count from different mills.

This chart shows a correlation of average values between Manual and UAK-1 + Neps Size Distribution Measurements from Fiber Beard in micron.

Table 5. Itru RXY Scatter ver 1.1 Test Results
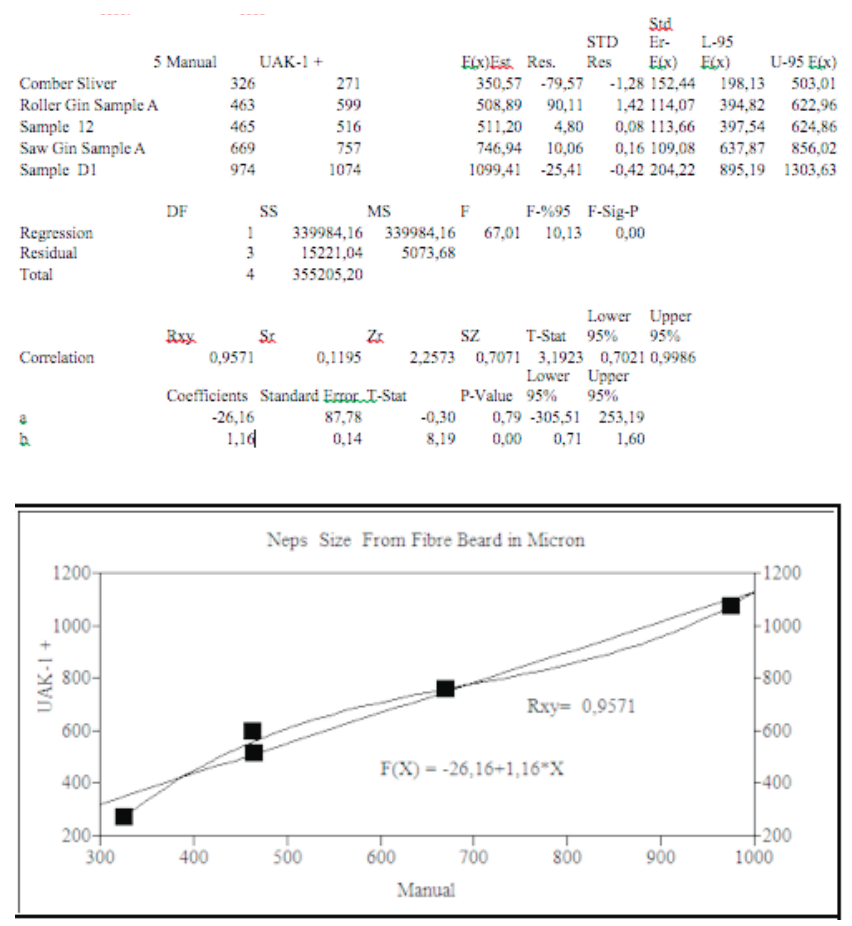

Figure 9. Neps size from fibre beard in micron

Karin [3] has also closely looked at neps in cotton fibers under microscope and found out that the number of neps counted is much higher than measured in other systems

\subsection{Samples of Neps Distribution Measurement and their importance in Spinning}

The most significant process in spinning to remove neps is combing machine. This clearly could be seen by measuring the neps distribution of Comber Noil and Comber Sliver. Combing Machine could also be controlled by Neps Testing of comber noil and its comber sliver as shown below: 


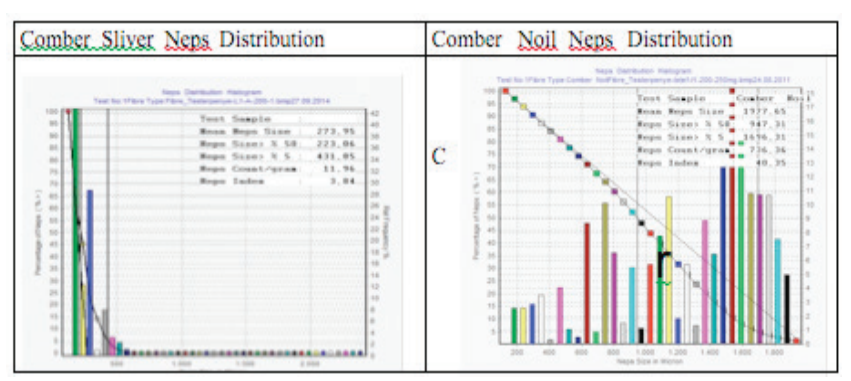

Figure 10. Sliver neps distribution

Neps Count per km yarn is also closely related to Neps Index $\%$ of comber sliver which is the percentage deviation from surface structure of fibre beard.

The chart shows the correlation between the Neps Count per $\mathrm{km}$ of combed yarn $(+200 \%)$ and Neps Index $(+120 \%)$ of Fiber Beard of Comber Sliver.is very high. Therefore, Neps Index of Fiber Beard of comber sliver could be used to estimate Neps count per km in yarn.

Table 6. Itru RXY Scatter ver 1.1 Test Results
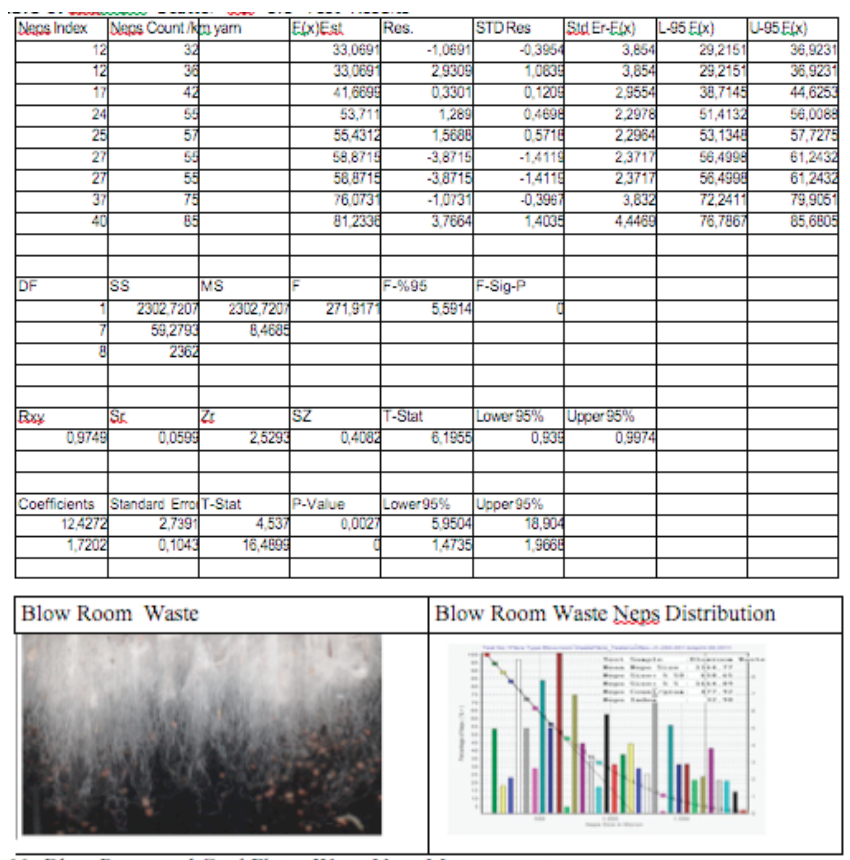

Figure 11. Blow Room and Card Flats Waste Neps Measurement

If the correct settings are not applied that will lead to high proportion of spinnable fibers as shown above and staple diagram of Blow-room waste.

Blow room removes small to largest neps but most of them are smallin size and immature fibre neps.
Testing of blow room waste in length could give some corrective actions for the setting the blow room machinery as in this case.(High content of spinnable Fibers)

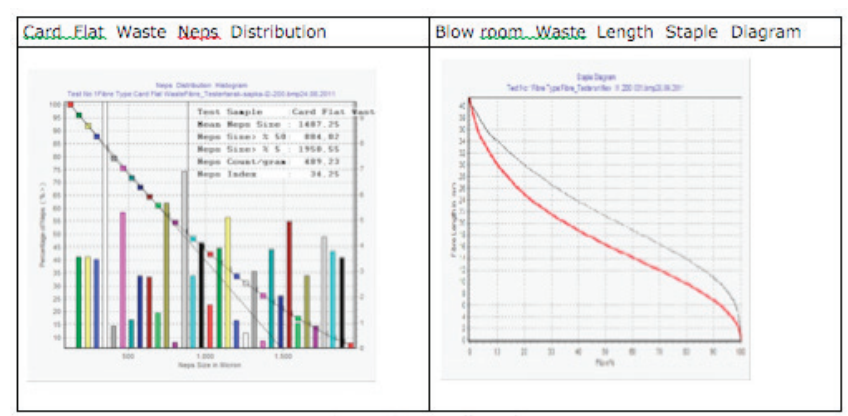

Figure 12. Neps disruption

Neps Distribution Charts and Test Results could be used to improve any stage of process and also machinery within each process. Every single stage of spinning process has an influence on the quality level of Yarn and also Mill Performance Level Processes after combing increases the Neps per $\mathrm{km}$ in yarn. By proper attention to technical data machine setting combed yarn quality could be improved as well as minimizing the comber noil and ring frame waste. $[4,5]$

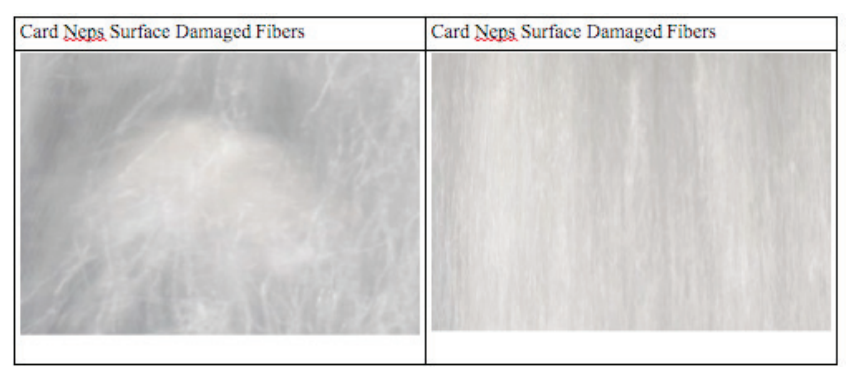

Figure 13. Neps surface of damaged fibers

There is a close correlation between mean Fiber length (LMS) and Short Fiber Content (SFN \%). Similar correlation exists between Mean Fiber Length (LG) and SFCW (Short Fiber Content by weight). Therefore as the LMS decreases short fibre content increases. An increase in the surface damaged fibers (SDFR \%) may lead to increase short fibers content in subsequent processes. Because the damages that occur on the perimeter of cotton fibers weaken the fibers and increase the coefficient of fibre friction. The similar problems exists in excessive top roller loading in drafting. This proves that the setting after combing plays an important role in yarn quality than as expected. 
The moving parts in blow room (openers, beaters) may damage the fibers more than as expected and these damaged fibers cannot be healed. And these damages cannot be identified measuring short fibre contents or neps per gram .Because their effects mainly observed in subsequent processes. Therefore, Neps distribution Histogram and SDFR \% could be effectively used to control surface damaged fibers along with Fiber Straightness CV \%: Neps distribution, SDFR \% and Fiber Straightness CV \% could be very well used to control previous processes such as ginning and subsequent processes such as carding to ring frame.

Surface damaged fibers increases the neps count in fibre. It is clear that as SDFR increases CV \% of Fiber parallelism or fibre straightness also increases and SFN \% short fibre contents by number also increases. The significance and importance of surface damaged fibers that once the fibers went to surface damage there is no way to remedy but remove. If the excessive surface damaged fibers not removed will cause many fabric defects in fabrics. Despite the good performance of blow room, cards and combers mill end up with unexpected yarn quality and high end breaks in spinning and weaving. In this case comber to ring frame process should be checked in terms of Surface Damaged Fibers and Neps Size Distribution.

\subsection{Fiber Beard Neps to Dyed Fabric Neps Relation}

Fiber to dyed fabrics correlations show that neps are closely correlated with each other especially at Neps size are larger in microns at $5 \%$ level. There is also another parameter closely related to dye take up variation that is ratio of Effective Fiber Length/Fiber X-Section Min Radius Ratio x1000: as this ratio increases neps in dyed fabrics also increases.

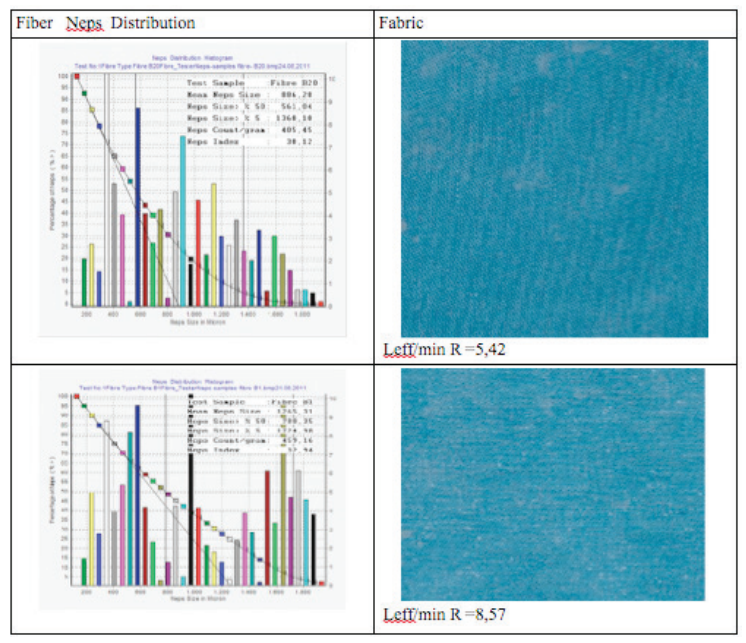

Figure 14. Fiber Neps Distribution
Higher the 5\% Neps on Fiber Beard more neps on Dyed Fabrics .LEF/Fiber X-Section Min Radius Ratio x1000 affects the processing neps .Longer, finer and more surface damaged fibers will lead to more processing neps.

\section{IMPROVING YARN QUALITY BY FIBER BEARD MEASUREMENT DATA}

\subsection{Fiber Straightness CV\%}

The function of carding and subsequent processes is to straighten fibre hooks and make the fibers parallel. The performance of these processes could be checked by Itru CV $\%$ Fiber Parallelism (Coefficient of Variation Percentage of Fiber Parallelism) parameter developed for the 1st time in the world. Fibre Straightness CV\% could be used to check off- standard running machinery and processing stages from bale to ring frame delivery. Fiber Straightness CV \%could be used to check-Machine Harvesting-Ginning ProcessGenetics and X-Breeding Research-Fiber/Machine behavior process control. Very high and very low $\mathrm{CV} \%$ of Fiber Straightness mainly caused by excessive ginning due to fibre breakage.

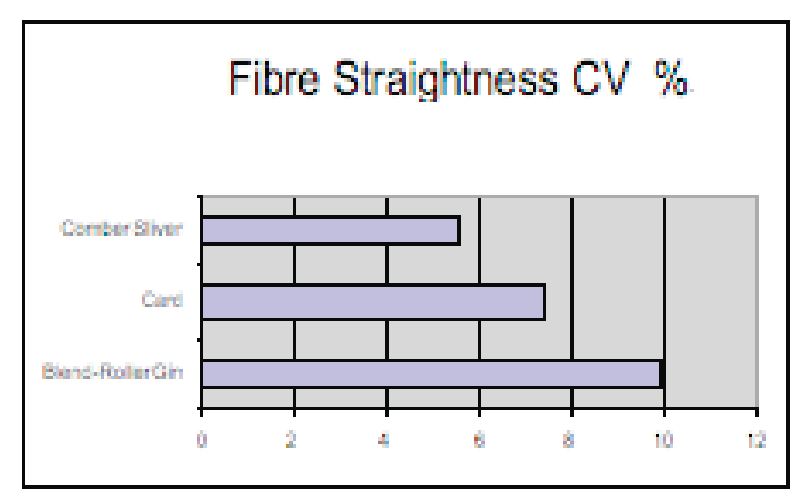

Figure 15. Fiber breaking strength

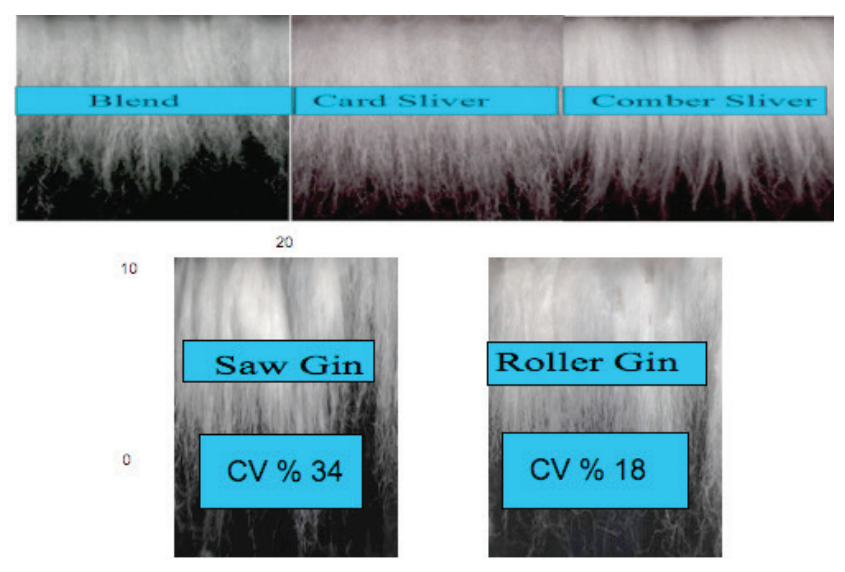


y Amount of Short Fibers less than 12,5 mm

y Amount of Short fibers less than $6,5 \mathrm{~mm}$

\ Straightening of hooked fibers and degree of fibre parallelism

\ Fiber breakage from x-section or Longitudinal level

\ Surface Damaged Fibers or peeling of fibre skin level

\White specks \%

> Cleanness \& Dirtiness

\ Neps content

\ Immature Fiber balls

y Different origins in the mixes not compatible with each other

When these values not controlled efficiently lead to

\ Lower efficiencies in spinning, weaving and knitting

\ High contents fabric defects such as pilling, white specks, dye take-up variation.

\ Variation within processing stages

\ Variation between processes

\ Variation within machinery

Variation between machinery

\ Could all be analyzed with Itru Fiber Tester UAK-1 + so that Optimum Quality with Minimum Manufacturing Costs could be achieved.

Coefficient of Variation of Fiber Straightness significantly affects the yarn quality especially after combing to ring frame over stretched and over drafted fibers will lead to deterioration of the yarn quality parameters mainly the imperfections as in the case shown in the processing charts.

\section{RESULTS AND DISCUSSIONS}

This research works cover three main sections;

a) Designing and construction of fully automated fibre testing machine which involves feeding cotton raw sample and also sliver to fibre clamp and cleaning the sample after the test.

b) Software to analyses the fibre beard image.

c) Compare the test results with practical applications:
1) Length measurement test results were compared with calibrated cotton samples.

2) Neps results were compared with actual yarn test results and also dyed fabric appearance.

3) Neps results were also compared with manual neps testing and their correlation of coefficients were included. In practical applications Fiber Surface Damages \% were related to peeling faults in the fabric.

\section{CONCLUSIONS AND FUTURE WORKS}

Histogram, Staple Diagram, and Fiber Graph could be efficiently plotted from the scanned image of fibre beard. Fiber Samples could be compared statistically at $95 \%$ confidence limits according to mean fibre length and CV\% and this approach could be used for classification-Process (Carded, Combed, Rotor and Air-jet) spinning. Fibers less than $6 \mathrm{~mm}$ in length are more closely related to neps (new short fibre content definitions related to Neps) CV \% of Fiber Straightness to check performance of machinery and processing stages.

Estimating Neps in dyed Fabrics from Fiber Beard Neps (Entangled Fibers Neps) Neps map and Neps Size distribution related to Fiber Surface structure from Fiber Beard Surface Damages Fibers \%(SDRF\%) could be used to predict unexpected yarn quality and fabric defects that may occur when most of the fibre properties are within limits as in the case of peeling faults and high imperfections in the yarn. Color variations and Neps in Dyed Fabrics could be estimated from the CMYK color Histogram and Itru Neps Size Distribution from Fiber Beard. Fiber Maturity, fiber Fineness mtex and implemented to the system for further developmenent.

\section{DISCLAIMER}

Mention of a trademark, warranty, proprietary product or vendor does not constitute a guarantee by the Itru Group Ltd and does not imply approval or recommendation of the product to the exclusion of others that may be suitable.

\section{REFERENCES}

[1] Béchir Azzouz, Ph.D., Mohamed Ben Hassen, Ph.D., Faouzi Sakli, Ph.D. , Adjustment of Cotton 
Fiber Length by the Statistical Normal Distribution: Application to Binary Blends, Journal of Engineered Fibers and Fabrics, Volume 3, Issue 3- 2008

[2] Chis Alan Braden, Inheritance of cotton fiber length and distribution, Doctor of philosophy, August 2005. pp-20-21.
[3] Jacobsen K. R., Grossman Y.L,Y Hsieh, Plant R.E., Lalor W.F., Jernstedt J. A.,. The Journal of Cotton Science 5:53-67 (2001)

[4] Com berNoil Settings (http://itru.net/ffis/Comber_ Data.pdf)

[5] Card Fiber Transfer Test (http://itru.net/ffis/card.pdf) 